\title{
OS PRINCÍPIOS DO LIBERALISMO E DO NEOLIBERALISMO E AS DIFICULDADES DA CRÍTICA' EM EDUCAÇÃO
}

\author{
Ged GuIMARÃES \\ Universidade Estadual de Goiás (UEG), Anápolis, Goiás, Brasil
}

\begin{abstract}
RESUMO: Neste artigo interrogam-se os princípios liberais e neoliberais e afirma-se que ambos desprezam o sentido político da vida dos homens, sobretudo os de inspiração neoliberal. Recorre-se a autores como Vernant (1996), Locke (1993), Keynes (1996), Smith (2012) e Marx (2013) para compreender a sociedade capitalista e dizer que, no âmbito da formação, ela pressupõe um indivíduo que saiba "operála"tecnicamente e que dificilmente as escolas e as universidades superam essa quase única finalidade. Conclui-se defendendo que a efetiva dimensão educativa impõe o sentido político no ofício de ensinar.
\end{abstract}

Palavras-chave: Indivíduo. Capitalismo. Formação. Crítica.

No plano da democracia o debate, as posições contrárias e até os conflitos constituem a normalidade das relações sociais. À margem da democracia os discursos, proferidos por poucos, minimizam os problemas e buscam estabelecer uma ordem social que protege um determinado número de indivíduos, eventualmente agrupados.

Quando os gregos, na Antiguidade Clássica, criaram a democracia eles não escondiam os conflitos, discutindo e decidindo os rumos da cidade em um círculo fechado de um palácio ou de um templo religioso, mas os enfrentavam em plena luz do dia. Vernant (1996) afirma que a cidade (pólis) torna-se então um "espaço mental", ou seja, ela não é somente um lugar com ruas, praças, monumentos e templos, e sim um ideal a ser construído todos os dias, cuja praça (ágora) é o lugar onde se encontram os desiguais, ricos e pobres, bem como os diferentes: os filósofos, os sofistas, os místicos e os céticos. Esse "espaço mental" expressa "o poder de união, Éris-Philia: essas duas entidades divinas, opostas e complementares, marcam como que dois polos da vida social." (VERNANT, 1996, p. 31, grifo do autor).

Mas, já entre os gregos, a palavra como instrumento de poder, ou seja, como expressão do espírito de Éris-Philia que tinha como fim o bem da cidade como morada dos humanos, perde para aqueles que a usam para auferir vantagens individuais. Então a palavra retorna aos espaços privados para esconder os conflitos e, por decorrência, ocultálos de todos, retirando-lhes o poder de compreendê-los e superá-los e, assim, negociá-los conforme os interesses daqueles capazes de impor as suas vontades, seja pelo terror que causa medo, seja pelo convencimento auferido daqueles a quem promete "abrigo e proteção". A pólis desaparece e a cidade passa a ser um lugar onde as pessoas moram e buscam tirar do ajuntamento a melhor vantagem. 
Talvez a expressão mais emblemática do desaparecimento da pólis, aquela que revela o ocaso da política como busca do "sumo bem", e que mesmo os gregos inicialmente a condenaram à cicuta ${ }^{2}$, seja a afirmação da então primeira ministra inglesa, Margaret Thatcher: "essa coisa [a sociedade] não existe. O que existe são homens, mulheres, indivíduos, famílias e empresas" (LANGE, 2019, s/p). Ora, quando um chefe de Estado faz afirmações como essa, e a sociedade não o manda para a "guilhotina", é porque a crise, compreendida como disputa entre indivíduos pela maior vantagem, já ganhou lastro e as pessoas nem se percebem mais como partes constitutivas da vida política, e têm a percepção da sociedade como um aglomerado de indivíduos em disputa pelo melhor quinhão.

A política abandona a "praça" e a ela só retorna de quando em quando. Ou seja, até que a "praça" seja novamente convocada, os escolhidos exercem os seus poderes como "os políticos", porque os homens abdicam da sua natureza, como diz Aristóteles, zoon politikon. As decisões tendem a ser tomadas conforme as vontades daqueles que falam em nome da "praça", esvaziada após o lapso de tempo em que o indivíduo exerce a liberdade ao depositar na urna o seu poder, perdendo-o em seguida por delegar a outro, no ato do voto, a condução da vida social.

Se, por um lado, os políticos tornam-se os profissionais da política - sejam eles do poder executivo ou legislativo -, por outro, a sociedade se desobriga dela ao delegarIhes a autoridade para discutir e deliberar sobre o que é melhor para todos que, sem a dimensão política, se veem reduzidos a pessoas agrupadas e em disputa por uma dada vantagem individual.

Esse espírito moderno, elevado ao limite, talvez tenha afinado a voz de Margaret Thatcher que, ouvida pelos negociantes, soou como uma bela melodia: essa coisa, a sociedade não existe, mas indivíduos, empresas... Eis o espírito dos liberais.

Cassirer (1992, p. 32 - 33), referindo-se ao espírito dos modernos, afirma que os homens estão "convictos de que se pode confiar no progresso da cultura intelectual, porque esse progresso, em virtude do impulso interior que o anima e da lei imanente que o governa, dará à ordem social sua nova e melhor forma". Ser melhor para os modernos só é possível se, de algum modo, o indivíduo aprender a economizar. Em outras palavras, o sentido da economia, compreendida como a busca da melhor norma para a casa, cujos cidadãos procuram elevar a convivência, é reduzido ao entendimento de como fazer para comprar barato e vender caro. Assim, seu sentido é individualizado, passando a ser um modo de vida previdente e uma condição sem a qual não é possível o progresso. Ou seja, fazer economia tornou-se poupar dinheiro, compreendido como expressão de algum bem, incluindo-se a força física, a energia mental, os sentimentos, os desejos. Tudo só faz sentido se implicar uma dada vantagem presente ou futura, cuja finalidade não pode ser outra senão aumentar um quantum de valor. Quem assim procede é porque aprendeu a poupar o tempo, ou a ganhá-lo. Não por acaso, a expressão mais repetida pelos negociantes - em tese, todos os indivíduos - é: "tempo é dinheiro".

O "progresso da cultura intelectual" não é outra coisa senão a disposição para o desenvolvimento, o crescimento do indivíduo. Quando os pais falam em educação, por exemplo, costumam pressupor a ideia de investimento, chegando a afirmar que esse é o melhor que podem legar a seus filhos, que se tornam uma espécie de depositário de um 
"garantido futuro". Assim, aquele que fizer bom uso desse investimento poderá ampliar a propriedade original, o próprio corpo, e realizar um dos princípios caros ao homem moderno, qual seja, o crescimento, cuja fonte não é outra senão o trabalho dos indivíduos, condição para o desenvolvimento e, por decorrência, o progresso.

Então, como afirma Locke (1983), o trabalho confere ao homem, por força individual, o direito de anexar ao próprio corpo o objeto resultado de seu esforço: "retirando-o do estado comum em que a natureza o colocou, anexou-lhe por esse trabalho algo que o exclui do direito comum de outros homens" (LOCKE, 1983, p. 45). Definido esse princípio, não é difícil imaginar o resto: qualquer que seja o modo como os indivíduos se arrumem, há que se preservar o direito de cada um, fundamento do direito privado. Em outras palavras, o direito privado deve ter a finalidade maior de proteger o "diligente e racional" (LOCKE, 1983, p. 47) e, assim, estarão criadas as condições para aumentar as reservas da humanidade. No fim, todos saem lucrando, ou podem lucrar.

Nessa linha de entendimento, os indivíduos agrupados são reduzidos a vendedores e compradores, seja qual for o lugar ocupado no processo produtivo. Eles estão sempre prontos para vender e comprar alguma coisa no mercado, ou seja, prontos para pôr em movimento a liberdade original que cada um traz em si, e buscar ampliar a propriedade, também original, mesmo que seja, no limite, o próprio corpo. Todos são considerados iguais e em condições de estabelecer um contrato, porque ninguém é formalmente preso a alguém, como nas sociedades anteriores, quando havia escravos ou servos. Há, pois, igualdade entre os indivíduos, mas, atomizados, ligam-se uns aos outros somente por força de uma necessidade contingente, pressuposta em algo a ser comprado ou a ser vendido.

Os modernos guardam em alta conta um modo de pensar individualista. Quando Locke (1983, p. 45) afirma que cada "homem tem uma propriedade em sua própria pessoa", pressupõe o indivíduo que pertence a ele mesmo e sobre ele não há ninguém com poder de lhe impor a vontade. Pressupondo também que todos são naturalmente iguais e livres, tudo que conquistarem o será em decorrência do "trabalho de seu corpo e a obra das suas mãos" (LOCKE, 1983, p. 45). Se cada um pensa assim, as questões de ordem geral - seguindo os argumentos de Locke (1983) - se equacionam com um "contrato social", cujos contratantes não podem prescindir de um Estado forte que, tal como um "remédio acertado" (LOCKE, 1983, p. 38), deve-se a ele recorrer apenas quando há a iminência de riscos para os contratantes.

Quando Keynes (2013), pouco mais de dois séculos depois de Locke (1983), fala em Estado forte, não é para ser como um remédio, mas como profilaxia. Ou seja, a sua presença deve ser constante em favor do bem-estar social. "O individualismo, se puder ser purgado de seus defeitos e abusos, é a melhor salvaguarda da liberdade pessoal, no sentido de que amplia mais do que qualquer outro sistema o campo para o exercício das escolhas pessoais" (KEYNES, 2013, p. 346). Segundo esse autor, o Estado intervencionista não vem para limitar ou impedir o espírito empreendedor de cada um, e sim inspirar um governo capaz de "evitar a destruição total das instituições econômicas" (KEYNES, 2013, p. 346), ou seja, a defesa do intervencionismo do Estado na economia não alcança a sua radicalidade. $O$ autor o defende no sentido da cooperação com a iniciativa privada: "Fora disso, não se vê nenhuma razão evidente que justifique um socialismo do Estado abrangendo a maior parte da vida econômica da nação. Não é a propriedade dos meios de produção que convém ao Estado assumir" (KEYNES, 2013, p. 345). 
Note-se, pois, que o espírito do capital é o condutor da ação intervencionista, ou seja, o que interessa é criar melhores condições para o diligente e racional. Para marcar a diferença fundamental do intervencionismo dos socialistas, Keynes (2013) afirma:

Se o Estado for capaz de determinar o montante agregado dos recursos destinados a aumentar esses meios [de produção] e a taxa básica de remuneração aos seus detentores, terá realizado o que lhe compete. Ademais, as medidas necessárias de socialização podem ser introduzidas gradualmente sem afetar as tradições generalizadas da sociedade. ${ }^{4}$ (KEYNES, 2013, p. 345, grifo nosso).

Então, o Estado precisa ser forte o suficiente para não permitir que indivíduos, agrupados ou isoladamente, Ihe imponham um modo de regulação. Nessa acepção, Keynes (2013) concebe o Estado num plano superior aos indivíduos que, democraticamente, devem ter direitos iguais para disputarem como deve ser a regulação do governo sem pôr em riscos a propriedade dos meios de produção, visando à promoção do bem-estar social.

Os neoliberais, ao contrário, interrogam o Welfare State e desejam abandonálo, compreendendo-o como expressão do atraso. Já no início do século XX, Mises (2009, p. 101), insatisfeito com os rumos do liberalismo, que para ele estava se corrompendo favoravelmente ao intervencionismo socialista, afirma: "No glorioso período do século $\mathrm{XIX}$, as notáveis realizações do capitalismo foram fruto das ideias dos economistas clássicos [...]. Precisamos, apenas, substituir más ideias por ideias melhores". As más são aquelas fundadas no princípio intervencionista do Estado, e as boas quando ele se limita a cuidar da segurança, único atributo aceito. Ao proporem o retorno aos economistas clássicos, ${ }^{5}$ os neoliberais do início do século XX desejam que se aprenda e defenda os fundamentos da economia de mercado.

Nessa linha de entendimento, não há governo eficaz se o Estado for intervencionista, pois estaria regulando a liberdade dos indivíduos. Sem a liberdade para se fazer comércio, observa Smith (2012, p. 21), "Todo homem precisaria prover-se de todas as coisas necessárias à vida e ao conforto de que necessitasse". Numa condição assim, talvez os homens nem tivessem existido, porque teriam "mutilado" a natural "propensão para a troca que originalmente leva à divisão do trabalho" (SMITH, 2012, p. 20). Ora, se a troca ou câmbio é um pressuposto humano e a liberdade lhe é inerente, então qualquer poder que se apresente com algum fiapo que limite ou impeça a troca livre deve ser afastado das relações dos indivíduos.

Esse princípio chega aos dias atuais de modo agressivo na denominação neoliberal. O Estado, no entendimento dos neoliberais, já regulamenta, já é intervencionista e deve ser retirado dessa centralidade em favor do mercado, aquele que sabe o que é melhor para os indivíduos porque é a expressão fiel da vontade de todos. Para Milton Friedman (2014, p. 23), "o que o mercado faz é reduzir sensivelmente o número de questões que devem ser decididas por meios políticos - e, por isso, minimizar a extensão em que o governo tem que participar diretamente do jogo", ou seja, a sua importância consiste em ser capaz de "interpretar e pôr em vigor as regras estabelecidas" (FRIEDMAN, 2014, p. 23) pelo mercado. Ora, se o Estado e a sua forma de governo não 
passa de "intérprete", a sua autoridade consiste em ser o "árbitro", cujo melhor é o que está atento às "regras" dos negócios, sempre em movimento e em mudança porque é a expressão dos indivíduos "naturalmente" livres.

É como se os princípios liberais do Welfare State tivessem aviltado os indivíduos. Para corrigir esse mal, os neoliberais defendem o Estado mínimo e que o próprio mercado seja o regulador de tudo, até mesmo dos órgãos públicos. Ou seja, quase nada deve pertencer ao Estado; e mesmo os órgãos centrais como os da justiça, segurança, parlamento e a administração direta do executivo devem "otimizar" a sua gestão conforme a das empresas naquelas partes em que não for possível ser terceirizada, seja na forma de uma Organização não Governamental (OnG), uma Organização Social (OS) ou até mesmo a indivíduos ad-hoc.

Quando os indivíduos ajuntados julgam que cada um pode valer mais que o dobro do outro, então tudo se torna confuso, estranho, assustador, numa palavra, bárbaro. Estamos falando do neoliberalismo, o que implica a redução do controle do Estado sobre os indivíduos. E, quando o Estado se põe como o promotor do investimento, a finalidade não é outra senão a de gerar oportunidades para que todos possam progredir, crescer e, por decorrência, o desenvolvimento do próprio Estado como na alcunha Welfare State. Embora este seja preferível àquele, ambos carregam o espírito individualista que busca criar condições para estender a "propriedade que cada um traz em sua própria pessoa".

Nota-se, no entanto, que o liberalismo e o neoliberalismo pressupõem o capitalismo como modo de organização. Ou seja, a propriedade privada dos meios de produção acaba se constituindo na materialidade da "mão invisível" de todos os indivíduos. A diferença consiste nas concepções de Estado: enquanto os defensores do Welfare State propugnam a centralidade da economia no Estado, os neoliberais o qualificam como "árbitro" das regras estabelecidas pelo mercado. Em qualquer das concepções há a centralidade no dinheiro, que busca sempre a sua valorização.?

No entanto, como o dinheiro não pode ir ao mercado sozinho, ele precisa de alguém que o conduza à boa multiplicação, alguém que seja capaz de expressar perfeitamente o seu desejo perene por valorização, o que, sob o capitalismo, será quem se deixa possuir pelo espírito do capital, tornando-se o seu estafeta. Marx (2011, p. 519), referindo-se a essa condição menor a que foi reduzida o homem, afirma metaforicamente: "Assim como o cervo grita por água fresca, o dinheiro grita por campo de aplicação para que o capital possa ser valorizado". Esse estafeta pode ser qualquer indivíduo, conforme os princípios neoliberais, mas pode ser também o Estado intervencionista dos defensores da regulação. No fim, quem está no comando são as leis do mercado com a sua "mão invisível", dizendo o que é melhor para ele: o espírito do valor e a sua valorização. Notese, pois, que o valor está no centro e exige a fidelidade de todos, sejam eles os indivíduos, seja ele o Welfare State.

Os detentores e controladores dos meios de produção no capitalismo são compradores e vendedores; no caso dos trabalhadores, sem nada para vender senão a própria força de trabalho, são vendedores e consumidores. Trata-se então da desigualdade material, pois enquanto aqueles compram e vendem com maior valor, estes são apenas vendedores e consumidores. O comum entre eles é a venda, pois se "o capitalista" compra de alguém a "disposição sobre o seu trabalho", ele só o faz porque 
está à venda "uma determinada habilidade" que esse trabalhador possui. (MARX, 2011, p. 220).

Quando o capitalista põe em movimento essa força comprada, ele a utiliza para a produção das mercadorias, objeto do seu empreendimento. O que interessa para ambos e os tornam iguais, porque em princípio têm a liberdade para cambiar, é o valor de venda: o valor da força de trabalho e o valor das mercadorias a serem vendidas. Não há trabalhador que não queira vender por maior valor a única coisa que possui, não há empresário que não queira vender por maior valor a sua mercadoria. $\mathrm{A}$ ambos não interessa a substância material do que é produzido. Ou seja, o valor de uso não passa de uma espécie de mal necessário para gerar valor em sua materialidade, o dinheiro. Se sob o capitalismo o objetivo dos indivíduos é esse, então o comando não lhes pertence, mas ao dinheiro que, na condição invertida, torna-se o sujeito.

Marx (2011, p. 105), referindo-se ao poder do dinheiro, afirma que "de objeto criado para facilitar a vida dos homens, o dinheiro [substância material do capital] tornase o sujeito por excelência", e os indivíduos ajuntados não passam de "coisas" portadoras de um valor, cujo "poder social, assim como o seu nexo com a sociedade, [eles trazem] consigo no bolso" (MARX, 2011, p. 105). Se o dinheiro torna o indivíduo grandioso é porque sabe valorizá-lo conforme manda as relações do mercado e assim ele será, como afirma Smith (2012, p. 534), "um amigo constante".

Se produzir trigo implicar em aumento do valor, que se produza trigo; se emprestar dinheiro a juros implicar em maiores lucros, que se destrua a plantação de trigo. E se um produtor se negar a queimar a lavoura em favor da produção e isso significar em perda de capital, então o próprio capital não o perdoa, correndo para os bolsos do concorrente, aquele que não se esqueceu de quem está no comando. $O$ dinheiro determina ao seu detentor como se deve controlá-lo, pressupondo sempre a sua multiplicação e, caso isso não ocorra, ele fatalmente correrá para aquele que melhor souber valorizá-lo, e terá um novo "fiel amigo".

Mesmo para Smith (2012, p. 533), a constância "desse amigo" - o dinheiro - se desfaz se o indivíduo não cuidar bem dele. Aquele que for "generoso ou pródigo" se tiver dinheiro, logo não o terá. O rico, ao contrário, é "frugal ou ávido por enriquecer", e somente assim ele revela o seu amor: o amor pelo dinheiro. Enquanto para Smith (2012) o amor é pelas instalações produtivas, pelas máquinas, pelas terras ou pelo dinheiro como um dos elementos da produção, para Marx (2013, p. 231), o amor é pelo capital enquanto "processo de valorização do valor", ou seja, o dinheiro como materialização do valor não tem outra finalidade senão a de valorizar a si mesmo: "o valor se torna, assim, valor em processo, dinheiro em processo [...] que cria [mais] dinheiro" (MARX, 2013, p. 231).

Marx (2013) dialoga com Smith (2012) por inversão: o dinheiro ama o seu bom investidor, aquele que, ao encarnar o valor, "põe ovos de ouro" (MARX, 2013, p. 231). Enquanto para Smith (2012) seria irracional destruir uma plantação de trigo, para Marx (2013), ao contrário, o valor lhe comanda à primeira faísca, se isso implicar em alguma vantagem. O obediente tem a passagem garantida para o "Olimpo" dos bons ganhadores de dinheiro; o desobediente cai em ruínas ao não passar pelo crivo do mercado, coisa que todos temem porque seria como se deixar governar por $\mathrm{Hades}^{8}$ e ter a companhia de 
Melinoe ${ }^{9}$, a deusa dos pesadelos, do fracasso, da tristeza, e talvez seja a companheira do próprio mercado quando entra em depressão econômica. ${ }^{10}$

Parece que sob o capitalismo os humanos foram despedaçados, pois, ao perderem a dimensão política da existência, tornaram-se reféns de Cerberus ${ }^{11}$, o monstro de três cabeças que vigia os mortais, neste caso, o valor, a sua valorização e sua forma dinheiro. Esse monstro, que tudo controla porque no fim ele se torna cada um dos indivíduos, se apresenta sob duas formas no ajuntamento dos indivíduos: a liberal e a excessivamente liberal, denominada neoliberal. Ambas têm uma mesma raiz ao buscarem um modo de "realizar" os princípios da liberdade, da igualdade e da propriedade que todos os indivíduos possuem para sempre progredir.

Então, o que une os modernos, a despeito da fé nos deuses das religiões ou do paganismo, não é outro elemento senão o dinheiro, que cada um possui e protege, ou o deseja. Neste caso, a amizade (Philía) se perde e o espírito de Éris - o Deus da guerra toma conta dos homens, porque no mercado, ou melhor, nos negócios, a amizade é deixada de lado. Não por acaso, recorre-se à frase "amigos, amigos, negócios à parte", quase como um mantra sagrado que não deixa o espírito dos homens nem mesmo quando se trata de relações familiares. Quem duvidar basta se lembrar de uma dada família em momentos de partilha de bens, sejam eles um terreno, um iate, uma máquina de costura, uma santinha.

Em sentido amplo, esses indivíduos são formados em suas relações com os outros e, no particular, nas instituições. Elas têm ensinado como operar esse mundo em suas várias especialidades e, enquanto não chegam a elas, são, sobretudo as relações familiares e as escolas fundamentais que cumprem essa finalidade, subsumindo aquele outro fim, qual seja, a formação do homem antes da profissão.

Os modernos, ao perderem a dimensão da política como pressuposto para a convivência e também quase abandonarem a busca pela melhor forma de coexistência, acabaram formando um ser vazio de humanidade ou, como afirma Rousseau $(1992$, p. 13) referindo-se aos homens dos "nossos dias", um "nada". O próprio Rousseau (1992, p. 13), já crítico das instituições das repúblicas, afirmara que "as palavras pátria e cidadania deveriam ser riscadas das línguas modernas" e, em não havendo mais preocupação com a vida social, não há sentido em se falar em formação para a cidadania. Segundo ele, o que nos restou tem sido isso: a formação de "um homem à venda." (ROUSSEAU, 1992, p. 25).

Parece que não se tem fugido disso nas ações pedagógicas, o que tem levado a um duplo problema: o mercado vem dispensando "esses homens à venda", e quase nada tem sido feito para a interrogação desse modo de vida. Se, por um lado, o mercado os dispensa por força da inovação tecnológica, que reduz os custos de produção, por outro, gera subconsumo porque diminui o poder de compra da massa de consumidores. E como o capitalismo pressupõe o encontro dos iguais nas relações de compra e de venda, pois em tese todos têm algo a negociar, então formar os indivíduos pensando em melhorar o valor de venda daquilo que possuem - mesmo que, no limite, seja a própria força de trabalho, a propriedade original - parece algo de um reino encantado.

Do mesmo modo, formar o cidadão compreendendo-o como potencial consumidor parece ser igualmente sem sentido, porque o próprio mercado o "exclui", e não há "ações afirmativas" que Ihe devolva efetivamente essa "cidadania". Jappe (2006, p. 12), referindo-se à finalidade da vida reduzida ao trabalho - ou a preparação para ele -, 
afirma que no capitalismo os indivíduos se põem "perante a absurda alternativa entre sacrificar a vida ao trabalho [...] e sofrer as consequências de não ter trabalho.".

Se esse rumo da vida dos indivíduos não tem levado a quase nada em termos de desenvolvimento humano, ou melhor, se a vida humana não tem melhorado apesar de todas as técnicas e das tecnologias disponíveis, além dos conhecidos modos de controle da natureza, então, sobretudo aqueles que trabalham com a formação devem procurar um modo de pôr a crítica no sentido de suas ações pedagógicas, conforme o seu universo de conhecimento. Para esse fim, talvez fosse necessário admitir algumas questões, como: Que modo de vida é esse em que se vive? Ele tem feito os homens melhores? Os humanos têm sido felizes? As respostas poderão ser encontradas no processo de compreensão do capitalismo.

Desde os gregos, na antiguidade, essas perguntas já eram feitas e se procurava respostas. Quando falavam em economia, por exemplo, no sentido original da palavra, buscavam a melhor norma para a casa, compreendida como morada dos homens, neste caso, a cidade (pólis). Essa morada seria tão melhor quanto os homens fossem melhores e, por isso, a vida era um permanente processo de formação (paideía) que, segundo Vernant (1986, p.34), começava com o primeiro suspiro e terminava com a morte, sempre buscando aprimorar a palavra, para eles, "um instrumento político por excelência".

Atualmente os homens perderam esse "instrumento", transferindo-o para os diversos representantes: reis, papas, presidentes, ministros, parlamentares, governadores, prefeitos, gestores, mídias. Vivendo em conformidade com os princípios, sobretudo neoliberais, essa perda se agrava porque leva os indivíduos, ao invés de enfrentar as dificuldades, próprias dos homens em relação social, a criar subterfúgios em forma de igrejas, terapias ad-hoc, coaching, shoppings ou a nomear mitos, heróis e até mesmo ditadores para conduzirem as suas vidas.

As relações não são políticas, ou democráticas, são individuais porque o que faz sentido é somente o eu e o outro, sendo esse outro aquele de quem se pode obter alguma vantagem. $O$ problema se radicaliza porque o outro também deseja o mesmo. Os neoliberais não veem nenhum problema aí, porque o capital os une. Já os defensores do Welfare State procuram fortalecer as instituições e assim evitar o confronto fatal dos indivíduos, diminuindo os riscos da República cair em ruínas. Embora estes sejam preferíveis àqueles, ambos pressupõem que o contato dos indivíduos consiste na oportunidade para um bom negócio, longe, pois, do sentido do encontro de humanos em busca da Excelência da vida política, o que faz o homem ser humano.

Quando o zoon politikon perde o seu adjetivo, o homem tende a ficar pior que os outros animais porque, não sendo preso à natureza como eles, lança mão da liberdade para buscar para si tudo o que há na terra e no espaço. Sem o poder da palavra, alienada a uma força estranha ou a alguém e sem a política, um modo de regular as relações sociais, os homens criaram para si a barbárie. O confronto de ideias, as diferenças, o conflito interior ou, em uma palavra, a crise, não é enfrentada pressupondo o zoon politikon, mas "um outro" de quem se pode obter algum lucro e de quem se deve defender, no limite, com uma boa arma de fogo de última geração. Se o indivíduo não tem limites, porque a política foi esvaziada de sentido, então aquele que mais se destaca, o que mais sucesso faz, torna-se o metrom, a unidade de medida para todos os outros. Assim, a vida social é 
GUIMARÃES, G.

reduzida a uma disputa que lembra alguns povos primitivos que se agrupavam por interesses imediatos, desfeitos quando a necessidade do agrupamento cessava.

Se atualmente a vida tem sido isso, então os educadores têm muito a contribuir em seus respectivos ofícios de ensinar, sejam eles das áreas das ciências, das artes, das letras, das tecnologias ou da filosofia. Por outras palavras, antes de se pensar em formar os indivíduos para as profissões ou para o mercado de trabalho, talvez fosse necessário pensar também, com mais intensidade, o que é um homem, o que é a vida e o que é a sociedade, olhando para essa em que se vive atualmente, qualificada neste artigo por ajuntamento de indivíduos. Ou seja, "se queres exercer influência sobre outros seres humanos, tu tens de ser um ser humano que atue efetivamente sobre os outros de modo estimulante e encorajador" (MARX, 2008, p. 161). Se a atual forma de "vida social" tem nos reduzido a uma mísera condição, então ela nos impõe a recusa de modo "estimulante e encorajador".

Artigo recebido em: 09/11/2019

Aprovado para publicação em: 02/03/2020

\section{THE PRINCIPLES OF LIBERALISM AND NEOLIBERALISM AND THE DIFFICULTIES OF CRITICISM IN} EDUCATION

ABSTRACT: In this article the liberal and neoliberal principles are questioned and it is argued that both despise the political meaning in life of men, especially those of neoliberal inspiration. It is based by the authors Vernant (1996), Locke (1993), Keynes (1996), Smith (2012) and Marx (2013), to understand capitalist society and to discuss about, in the context of academic formation, it presupposes an individual who knows how to operate it technically and schools and universities hardly overcome this almost single purpose. It is concluded by arguing that the effective educational dimension imposes political meaning in the profession of teaching.

KEYWORDS: Individual. Capitalism. Formation. Criticism.

\section{LOS PRINCIPIOS DEL LIBERALISMO Y DEL NEOLIBERALISMO Y LAS DIFICULTADES DE LA CRÍTICA EN LA EDUCACIÓN}

RESUMEN: En este artículo se cuestionan los princípios liberales y neoliberales, afirmándose que ambos desprecian el sentido político de la vida de los hombres, sobretodo los de insipiración neoliberal. Se recurre a autores como Locke (1993), Vernant (1996), Keynes (1996), Smith (2012) y Marx (2013) para compreender la sociedade capitalista y afirmar que, en el ámbito de su formación, ella presupone un individuo que sepa manejarla tecnicamente y que dificilmente las escuelas y universidades sobrepasan esa casi única finalidad. Se concluye defendiendo que la efectiva dimensión educativa impone el sentido político del oficio de enseñar.

PALABRAS CLAVE: Individuo. Capitalismo. Formación. Crítica. 


\section{NOTAS}

1) Adjetivo que em grego é "saber fazer distinção", "estar seguro para tomar decisão entre posições contrárias". Como substantivo é "crise", ou seja, momento difícil, conflituoso, agonizante, momento que exige separação, ruptura. A palavra, como instrumento de poder, é prenhe. Dela sai alguma coisa e todos esperam que seja o melhor para todos.

2) Os gregos, ao condenarem à morte, conduziam ao apenado um cálice de cicuta, um veneno. $\mathrm{O}$ exemplo clássico é a morte de Sócrates, acusado e condenado pela cidade Atenas.

3) Cf. Aristóteles. (Política, 1252 a 3-5).

4) Grifo nosso.

5) Keynes (2013) se refere especialmente aos economistas ingleses Adam Smith (1723) e a David Ricardo (1817).

6) Cf. Smith, 2012, p. 567.

7) Compreende-se que, sob o capitalismo, a vida é reduzida a produção do valor em sua materialidade, o dinheiro. Partimos de Marx (2011) para tecer a crítica a esse modo de vida e também a autores como Kurz (2014), Jappe (2016) e Scholz (2016).

8) Na mitologia grega, as almas seriam julgadas por Hades. As melhores iam para o Olimpo, lugar claro, vivo e para onde todos desejavam ir, e que se contrapunha ao invisível mundo escuro dos mortos, governados por Hades.

9) Filha do Deus Hades, Melinoe era a deusa dos espectros, dos pesadelos, da ruína.

10) Para os economistas há depressão quando o consumo das mercadorias é reduzido drasticamente, há alta taxa de desemprego, escassez de crédito, investimento reduzido, deflação ou inflação. Trata-se, pois, de crise do capitalismo porque não há crescimento, progresso, desenvolvimento e, por decorrência, o valor dinheiro não se valoriza com a constância desejada. Assim, os indivíduos ficam sem esperança e, como não há capitalismo sem aqueles que o faz, então ele fica "deprimido" porque expressa a tristeza que acomete cada um dos seus "estafetas".

11) Cérberus era representado por um cão de três cabeças que guardava a morada dos mortos e da sua vigilância ninguém escapava quando para lá era conduzido.

\section{REFERÊNCIAS}

ARISTÓTELES. A política. Trad. de Antônio Campelo e Carlos de Carvalho Gomes. Lisboa: Vega, 1998.

CASSIRER, E. A filosofia do iluminismo. Trad. de Álvaro Cabral. Campinas: Editora da UNICAMP, 1992.

FRIEDMAN, M. Capitalismo e Liberdade. Trad. de Afonso Celso da Cunha Serra. Rio de Janeiro: LTC, 2014.

GAULEJAC, V. Gestão como doença social. Trad. de Ivo Storniolo. Aparecida, São Paulo: Idéias \& Letras, 2007.

JAPPE, A. As aventuras da mercadoria - para uma nova crítica do valor. Trad. de José Miranda Justo. Lisboa: Antígona, 2006. 
GUIMARÃES, G.

KEYNES, J. M.. A teoria geral do emprego, do juro e da moeda. Trad. de Mário R. da Cruz. São Paulo: Editora Nova Cultural, 1996.

KURZ, R. Dinheiro sem valor. Trad. de Lumir Nahodil. Lisboa: Antígona, 2014.

LANGE, M. Margaret Thatcher. a sociedade não existe! (reflexão). Disponível em: https://michaelllange.com/2015/11/14/margaret-thatcher-asociedade-nao-existereflexao/ - Acesso em 20 out. 2019.

LOCKE, J. Segundo tratado sobre o governo. Trad. de Anoar Aiex e E. Jacy Monteiro. São Paulo: Abril Cultural. 1983. (Col. Os pensadores).

MARX, K. Grundisse. Trad. de Mário Duayer e Nélio Schneider. São Paulo: Boitempo, 2011.

MARX, K. O capital. Trad. de Rubens Enderle. São Paulo: Bointempo, 2013.

MARX, K.Manuscritos econômico-filosóficos. Trad. de Jesus Ranieri. São Paulo: Boitempo, 2008.

MISES, L. V. As seis lições. Trad. por Maria Luiza Borges. São Paulo: Instituto Ludwig Von Mises Brasil, 2009.

ROUSSEAU, J-J. Emílio. Trad. de Sérgio Milliet. Rio de Janeiro: Bertrand Brasil. 1992.

SCHOLZ, R. VIVA O FETICHE! Sobre a dialética da crítica do fetichismo no atual processo de 'Colapso da modernização'. Ou: quanto establishment pode suportar a crítica social radical? Trad. de Tradução de Boaventura Antunes. Disponível em: http://www.obecoonline.org/roswitha\%20scholz18.htm. Acesso em: 22 nov. 2016.

SMITH, A. A riqueza das nações. Trad. de Alexandre Amaral Rodrigues e Eunice Ostrensky. São Paulo: Martins Fontes, 2012.

VERNANT, J. P. As origens do pensamento grego. Trad. de Ísis Borges B. da Fonseca. São Paulo: Difel, 1986.

Ged Guimarães: Possui graduação em Pedagogia pela Pontifícia Universidade Católica de Goiás (1987), mestrado em Educação pela Universidade Federal de Goiás (1993) e doutorado em Educação pela Universidade Federal de Minas Gerais (2004). É PósDoutor em Filosofia da Educação pela Universidade do Minho, Braga, Portugal (2013). Professor da Universidade Estadual de Goiás - UEG/Anápolis-GO, atuando na PósGraduação - Mestrado Interdisciplinar em Educação, Linguagem e Tecnologias - PPG-IELT da UEG/Anápolis-GO. 
Os princípios do liberalismo e do neoliberalismo...

Dossiê 107

Orcid: https://orcid.org/0000-0001-8261-2833

E-mail: suimaraesged@smail.com

Este periódico utiliza a licença Creative Commons Attribution 3.0, para periódicos de acesso aberto (Open Archives Iniciative - OAI). 